\title{
A Double-Blind, Placebo-Controlled Trial of Modafinil for Cocaine Dependence
}

\author{
Charles A. Dackis, M.D. ", Kyle M. Kampman, M.D. ${ }^{*}$ Kevin G. Lynch, Ph.D.., Jennifer G. \\ Plebani, Ph.D.", Helen M. Pettinati, Ph.D.", Thorne Sparkman, M.D. , and Charles P. O'Brien, \\ M.D., Ph.D.* \\ *University of Pennsylvania School of Medicine, Philadelphia, PA 19104
}

\section{Abstract}

This is a randomized, double blind, placebo-controlled study of modafinil treatment for cocaine dependence. Patients $(n=210)$, who were actively using cocaine at baseline, were randomized to 8weeks of modafinil ( $0 \mathrm{mg} / \mathrm{day}, 200 \mathrm{mg} /$ day or $400 \mathrm{mg} /$ day) combined with once-weekly cognitive behavioral therapy (CBT). Our primary efficacy measure was cocaine abstinence, based on urine benzoylecgonine (BE) levels, with secondary measures of craving, cocaine withdrawal, retention and tolerability. We found no significant differences between modafinil and placebo patients on any of these measures. However, there was a significant gender difference in that male patients treated with $400 \mathrm{mg} /$ day tended to be more abstinent than their placebo-treated counterparts $(\mathrm{p}=0.06)$. Our negative findings might be explained by gender differences and/or inadequate psychosocial treatment intensity in patients with severe cocaine dependence.

\section{Keywords}

modafinil; cocaine; pharmacotherapy; abstinence; addiction

\section{INTRODUCTION}

Cocaine dependence is a rapidly progressive disorder associated with numerous devastating medical, psychiatric and psychosocial hazards. Unlike alcohol, opiate and nicotine dependence, there are no FDA approved pharmacological agents for cocaine dependence and current treatment approaches are typically limited to inpatient or intensive outpatient rehabilitation for severely addicted individuals. These psychosocial approaches are associated with disappointing clinical outcome because most patients are unable to resist craving and the lure of cocaine euphoria. Cocaine euphoria provides a particularly

\footnotetext{
(C) 2012 Elsevier Inc. All rights reserved. discovered which could affect the content, and all legal disclaimers that apply to the journal pertain. access to all study data and take responsibility for the integrity of the data and the accuracy of the data analysis. Study concept and design: Drs. Dackis, Kampman, Pettinati, O’Brien, Lynch

Statistical expertise: Drs. Lynch and Plebani

Obtained funding: Dr. Dackis

Administrative, technical, or material support: Drs. O’Brien, Pettinati, Kampman, Sparkman

Study supervision: Drs. Dackis and Kampman
}

Correspondence should be directed to: Kyle M. Kampman, M.D., University of Pennsylvania Treatment Research Center, 3900 Chestnut Street, Philadelphia, PA 19104, Phone: (215) 222-3200, Fax: (215) 222-3807, kampman_k@ mail.trc.upenn.edu.

Publisher's Disclaimer: This is a PDF file of an unedited manuscript that has been accepted for publication. As a service to our customers we are providing this early version of the manuscript. The manuscript will undergo copyediting, typesetting, and review of the resulting proof before it is published in its final citable form. Please note that during the production process errors may be

Author Contributions Dr. Dackis, as principal author of this article, and Dr. Lynch, as principal statistician for the analysis, had full 
formidable barrier to recovery and its sheer power is perhaps best illustrated by the fact that laboratory animals will consistently self-administer cocaine to the point of death. Modafinil has been reported to blunt cocaine-induced euphoria in controlled human laboratory studies by three separate research groups utilizing different study designs. We first reported euphoria blockade in a drug interaction safety study of oral modafinil combined with openlabel intravenous cocaine (Dackis et al., 2003), and our finding was subsequently replicated by two studies assessing the combination of modafinil with intravenous (Malcolm et al., 2006) and intrapulmonary (crack) (Hart et al., 2008) cocaine. The latter study also found reductions in the self-administration of crack cocaine by modafinil-treated patients, suggesting that euphoria blockade by modafinil might reduce cocaine consumption in the clinical setting. All three studies demonstrated medical safety when modafinil and cocaine were co-administered. We also reported excellent tolerability in an 8-week open-label trial of modafinil ( $200 \mathrm{mg} / \mathrm{day}$ and $400 \mathrm{mg} /$ day) in cocaine dependent patients ( $\mathrm{n}=17)$ who spontaneously reported reduced or absent euphoria after using cocaine (Dackis \& O'Brien, 2003).

Modafinil was subsequently reported to promote abstinence in two clinical trials. We conducted a randomized, controlled pilot study $(n=62)$ in "pure" cocaine dependent patients (i.e., those lacking other substance dependence except nicotine) and reported that patients treated with modafinil $(400 \mathrm{mg} /$ day $)$ attained significantly more cocaine abstinence $(\mathrm{p}<0.03)$ according to objective urine BE testing (Dackis et al., 2005). The modafinil-treated patients also attained significantly longer periods of abstinence $(\mathrm{p}<0.05)$ than those treated with placebo. These findings generated considerable interest in modafinil and we now report one of three government-funded studies that were launched to further assess this agent as a potential first-line treatment for cocaine dependence. A recently published multi-site trial $(n=210)$ reported that patients randomized to modafinil $(200 \mathrm{mg} /$ day and $400 \mathrm{mg} /$ day $)$ experienced significantly less craving $(\mathrm{p}<0.04)$ and more consecutive cocaine non-use days $(\mathrm{p}<0.02)$, but overall cocaine use was not significantly reduced in the modafinil compared to placebo-treated patients (Anderson et al., 2009). However, this multi-site study included many patients who were dependent on cocaine and alcohol (about 41\%), and a post hoc analysis found that the "pure" cocaine patients who never met criteria for alcohol dependence attained a significantly greater rate $(p<0.02)$ and duration $(p<0.01)$ of cocaine abstinence with modafinil treatment when compared to placebo.

The current study was designed to exclude alcohol dependent patients, although the original rationale was based on the fact that cocaine and alcohol produce opposite neuroadaptations in reward-related brain pathways. Chronic cocaine exposure depletes glutamate levels (Bell et al., 2000; Hotsenpiller et al., 2001; Kalivas \& Duffy, 1998; Keys et al., 1998) and downregulates glutamatergic neurotransmission (Thomas et al., 2001) in the striatum, while chronic exposure to alcohol increases glutamate levels (more than 250\%) (Rossetti \& Carboni, 1995) and up-regulates glutamate receptors (Trujillo \& Akil, 1995) in this rewardrelated region. We initially proposed modafinil, a glutamate-enhancing agent, as a means of normalizing glutamate neuroadaptations in cocaine dependence (Dackis \& O'Brien, 2003), and we excluded alcoholic patients because glutamate is up-regulated in alcoholism (Dackis \& O'Brien, 2003). It is therefore not surprising that the multi-site study found that modafinil was not effective in alcohol dependent patients.

Aside from attenuating cocaine euphoria and reversing neuroadaptations associated with chronic cocaine exposure, modafinil also provides agonist effects for cocaine dependent patients. The mechanism of cocaine reward is largely ascribed to dopamine transporter (DAT) blockade (Dackis, 2005), and it has been known for some time that modafinil is a weak DAT blocker (Mignot et al., 1994). DAT blockade mediates modafinil's stimulant effect in animals (Zolkowska et al., 2009), and a recent neuroimaging study demonstrated 
that therapeutic doses of modafinil produce DAT blockade in humans (Volkow et al., 2009). This latter finding fanned recent controversy over the possibility that modafinil, which has been designated as a Schedule IV medication (under the Controlled Substances Act) since its approval in 1998, might produce euphoria and lead to addiction (O'Brien et al., 2006). However, human laboratory studies evaluating the subjective effects of modafinil do not report significant stimulant effects (Jasinski, 2000; Jasinski \& Kovacevic-Ristanovic, 2000; Rush et al., 2002; Volkow et al., 2009; Vosburg et al., 2009; Warot et al., 1993) and postmarketing surveillance has not revealed evidence of abuse (Myrick et al., 2004). Animal studies similarly report that modafinil is not self-administered by cocaine-naïve rats (Deroche-Gamonet et al., 2002), and only self-administered at extremely high doses by cocaine-maintained monkeys (Gold \& Balster, 1996). Despite its ability to block the DAT and increase dopamine levels in reward circuits, the abuse potential of modafinil is limited by slow onset after oral administration, and its instability at high temperatures and relative insolubility in water makes modafinil unsuitable for intrapulmonary and intravenous administration. We carefully monitored the abuse potential of modafinil in our prior trial by analyzing the pill return rates of our subjects who were provided with extra pills each week in case they missed a study session, and there was no difference in pill return rates between the modafinil and placebo treated subjects (Dackis et al., 2005). These considerations suggest that modafinil does not have significant abuse potential and can be safely administered to cocaine dependent patients.

\section{MATERIALS AND METHODS}

\section{Study Participants}

We randomized 210 treatment-seeking patients ( 157 male, 53 female) with a mean age of 44.5, SD 8.7; age range 22-60) from the greater metropolitan Philadelphia area to take part in this trial. The University of Pennsylvania Human Investigations Committee (IRB) approved our protocol and all print advertisements that were used for recruitment. Patients provided written informed consent to participate in the trial and demonstrated their comprehension by completing a quiz that was re-administered until all questions were answered correctly. Patients met Diagnostic and Statistical Manual of Mental Disorders (DSM-IV-TR) criteria for cocaine dependence, used at least $\$ 200$ worth of cocaine in the past 30 days, and were required to provide at least one cocaine-positive urine sample during screening as measured by a quantitative BE assay. Individuals were excluded from the study if they were dependent on any other substance (except nicotine) or had active and serious medical or psychiatric illness. We also excluded individuals with a history of bipolar disorder, taking psychotropic medications or agents that could interact with modafinil, or having abnormal baseline laboratory findings. Pregnant women were excluded and women of childbearing potential were only randomized if they agreed to use acceptable birth control methods.

\section{Study Design}

This was a randomized, double blind, placebo-controlled 8-week trial of modafinil for cocaine dependence. The study was conducted at the University of Pennsylvania Treatment Research Center's outpatient facility, and its objective was to evaluate the efficacy of modafinil treatment for cocaine dependence based on quantitative BE levels and selfreported use. Enrollment occurred over a 3-year period (June 2004 through November of 2007) and the study was completed in March of 2008. A 2-week screening period (3-4 visits) included a comprehensive medical history, physical examination, typical clinical laboratory studies (blood chemistries, complete blood count, liver function tests, urinalysis, urine pregnancy test if female), vital signs and a 12-lead electrocardiogram (ECG). This entire medical evaluation was repeated within one week of study medications 
discontinuation. The diagnosis of current cocaine dependence was established with a Structured Clinical Interview for DSM IV (SCID) (First et al., 1996), and other psychiatric disorders were ruled out with the Mini-International Interview (Sheenan et al., 1997). After screening, 210 eligible patients were randomized with a computer-generated code (Randomization.com) to modafinil $200 \mathrm{mg} /$ day (M200; $\mathrm{n}=65$ ), modafinil $400 \mathrm{mg} / \mathrm{day}$ (M400; $\mathrm{n}=70$ ) or matching placebo (PLAC; $\mathrm{n}=75$ ) for the 8 -week treatment course. A research pharmacist generated the allocation sequence, provided group assignment, and was solely aware of the medication assignment code that was only available for emergency access. Research personnel who enrolled, treated, and assessed the patients were unaware of patient assignments. Urn randomization was used to stratify patients across the experimental conditions based on gender and frequency of cocaine use (low use $₫ 0$ days/month; high use $>10$ days/month). The study physician dispensed study medications (modafinil and matched placebo supplied by Cephalon, Inc.) on a weekly basis in blister packs that contained a 9-day supply to address the possibility of missed visits. Patients were paid $\$ 5$ for each returned blister pack to facilitate accurate pill counts. Study medications were initiated at the end dose ( $0 \mathrm{mg}, 200 \mathrm{mg}$ or $400 \mathrm{mg}$ as a single morning dose) by providing 4 pills/day, with each containing either modafinil $0 \mathrm{mg}$ or modafinil $100 \mathrm{mg}$, and the study medications were discontinued after 8 weeks without taper.

Patients were instructed to attend three clinical research visits per week and provide a urine sample during each visit for cocaine (BE), which was analyzed by gas chromatography mass spectrometry (GCMS). In order to assure urine sample validity, we measured urine temperatures at the time of collection and only acceptable samples (between $94^{\mathrm{O}}$ and $99^{\mathrm{O}}$ Fahrenheit) were analyzed. A research technician evaluated the patients during each visit and the study physician conducted weekly assessments of adverse events, global improvement and concomitant medications on standardized forms. Individual, manualguided CBT (adapted for treating substance dependence) (Kadden et al., 1992) was provided once weekly (total of 8 sessions) with audio-taped supervision to assess manual adherence. Safety data were also collected weekly, including blood pressure, pulse, temperature, body weight, urine testing for other substances and adverse events. Three follow-up assessments were scheduled one week, one month, and three months after the study medications were discontinued.

\section{Outcome Measures, Schedule of Assessments, and Sample Size}

The primary measure of efficacy was cocaine use based on thrice-weekly quantitative urine BE assays. We hypothesized that modafinil-treated patients would supply more BE-negative urines, indicating (1) cocaine abstinence and (2) study visit attendance, than the placebotreated patients. BE concentrations $\geq 300 \mathrm{ng} / \mathrm{ml}$ were considered to be cocaine positive. Our secondary efficacy measures included the physician-rated Clinical Global ImpressionObjective Scale (CGI-O) (Guy, 1976), the Brief Substance Craving Scale (BSCS) (Somoza et al., 1995), and the Cocaine Selective Severity Assessment (CSSA) (Kampman et al. 1998), which were rated weekly, and three times/week assessments with the Timeline Follow-Back Interview (TLFB) method (Sobell \& Sobell, 1992) and the Clinical Global Impression Scale-Subjective Scale (CGI-S) (Guy, 1976). Additional clinical and psychosocial characteristics were assessed at baseline and three follow-up meetings with the Addiction Severity Index (ASI) (McLellan et al., 1992), Hamilton Rating Scale of Anxiety (Ham A) (Hamilton, 1969), Hamilton Rating Scale of Depression (Ham D) (Hamilton, 1967), Beck Depression Inventory (BDI) (Beck et al., 1974) and the Symptom Checklist 90Revised (SCL90-R) (Derogatis, 1977). We based the number of patients in each group on previous NIDA cocaine studies and the effect size of our earlier modafinil pilot study (Dackis et al., 2005). 


\section{Statistical Analysis}

This is an intent-to-treat analysis in which patients were first compared on a variety of baseline characteristics. We used chi-square tests for categorical characteristics and t-tests for continuous characteristics to assess randomization balance across the three treatment groups. The primary analyses did not include additional covariates, although we planned a priori to include characteristics that showed significant imbalance across the groups as covariates in a supplementary analysis. In our primary analyses of the repeated UDS measures, we used generalized estimating equation (GEE) models (Diggle et al., 2002) to analyze repeated binary outcomes obtained from the quantitative BE assays. Missing urines were imputed as positive, which is an accepted practice in cocaine trials (Shoptaw et al., 2002). To assess the influence of missing UDS measures, we also performed GEE and mixed effects analyses of the UDS measures with missing UDS tests ignored. GEE and mixed effects models were also used to analyze other repeated outcomes (CGI-O, CGI-S, TLFB, CSSA, BSCS, HAM-A, HAM-D BDI). GEE models assume that data are missing completely at random (MCAR) and do not require correct specification of the within subject covariance structure, while mixed effects models assume only missing at random (MAR) but require correct specification of within subject covariance structure, so the two sets of models provide mutual checks of the two types of model assumptions. Our primary models included terms for treatment groups, and for polynomial time effects. We also examined whether group by time effects improved the fit of the model. In fitting these models to the data, terms significant at the 5\% level were included in the GEE models, as were lower order effects contained in a significant interaction. Empirical standard errors (Wald and Score statistics) were used to assess significance.

\section{RESULTS}

\section{Baseline Measures}

There were no significant differences ( $p>0.05$ ) between the M200, M400 and PLAC groups on a battery of measures drawn from the baseline ASI, TLFB, Ham A, Ham D, BDI, SCL-90, and CSSA. There were also no baseline differences when the male patients were analyzed separately. A selection of important baseline demographic, clinical, and psychosocial characteristics of randomized patients are listed in Table 1.

\section{Pill Compliance}

We obtained pill compliance data on 193 out of 210 patients. The other 17 dropped out of the study after fewer than four visits. There were no significant differences among the M200, M400 and PLAC groups on pill compliance or on the rate of return for extra pills supplied in the blister packs, which is a measure of possible overuse. A total of 147 patients ( $\mathrm{n}=55$ PLAC, $\mathrm{n}=41$ M200, n=51 M400) had at least 1 week where they did not return all of the 8 extra pills in their weekly blister packs, which contained a 9-day supply to be used in the event of a missed session. A Chi-square test showed no difference between the groups in the proportion of patients with at least one such week (Chi-square $(2)=1.79, p=0.41)$. An ANOVA test of the number of weeks of extra pill retention showed no differences among the three groups $(\mathrm{F}(2,190)=0.38, \mathrm{p}=0.69)$. Across weeks in which expected pills were not returned, the mean 8-week number retained in the PLAC (10.9, SD=11.1), M200 (9.8, $\mathrm{SD}=9.1)$ and $\mathrm{M} 400(10.1, \mathrm{SD}=9.4)$ groups were very similar, and there was no difference found across the treatment groups by ANOVA test $(\mathrm{F}(2,190)=0.23, \mathrm{p}=0.80)$. When queried, patients typically stated they could not recall what happened to the missing pills. Three modafinil-treated and 4 placebo-treated patients retained more than 16 of the extra 64 pills supplied over 8 weeks. 


\section{Therapy Visits}

Each participant could have had eight CBT sessions during the treatment phase. The mean numbers of sessions attended were $4.4(\mathrm{SD}=2.8)$ for the placebo group, 5.2 (2.6) for the modaf 200 group, and 5.2 (2.6) for the modaf 400 group. There was a significant difference between the groups (Chi-square $(2)=6.85, \mathrm{p}=0.03$ ) with the plavcebo group having significantly fewer sessions than either of the two modafinil groups ( $\mathrm{p}=0.02$ in each case).

\section{Treatment Retention}

At the end of eight weeks, 40/65 (61.5\%) of M200 patients and 43/70 (61.4\%) of M400 patients were still retained in the study, compared to only $37 / 75$ (49.3\%) in the PLAC group. Alternatively, with dropout defined as failing to complete the first 2 weeks of treatment, there were 8 dropouts in the M200 group, 5 in the M400 group and 11 in the PLAC group (Chi-square $(2)=2.10, \mathrm{p}=0.35$ ).

\section{Cocaine Outcomes}

Our primary outcome was cocaine use measured by thrice-weekly quantitative urine BE levels and TLFB self-reported use. We followed the guidelines of Preston (Preston et al., 1997) to create a set of "new use" indicators based on the combined TLFB and BE results, and to determine an initial set of cocaine use indicators for each day of the treatment period. However, we found very poor concordance between the TLFB and BE levels. The minimal recommended concordance of $70 \%$ was primarily seen in patients with very little cocaine use, and concordance decreased as BE levels increased. We ran all analyses on the simple BE-based indicators of cocaine use and on the Preston-rule indicators. While there were small numerical differences between the two sets of analyses, the inferences regarding the efficacy of modafinil were the same across the simple and Preston indicators. Accordingly, we opted to ignore the TLFB self reports in our analyses, and instead base all comparisons on the objective BE data.

\section{Missing Data Issues}

The design called for 24 urine samples from each of 210 patients, giving a total of 5040 planned BE tests. The actual total number of visits attended was 3318, or about $66 \%$ of those planned. The missed visits were split about equally between visits missed after drop out (872) and those missed intermittently (850). As described above, there were no significant differences in rates of treatment retention to the end of 8 weeks and the groups did not differ on other dropout measures. More than half of the modafinil-treated patients were retained through 8 weeks with a median time to the last visit of 24 for each group. The median time to the last visit for the PLAC group was 23 visits. The within group means for the last visit attended were PLAC (M=19.03, SD=7.69), M200 ( $M=20.23, S D=7.23)$, and $\mathrm{M} 400(\mathrm{M}=20.37, \mathrm{SD}=6.70)$. A log-rank test showed no significant difference in the distribution of time to drop out (Chi-square $=2.96, \mathrm{df}=2, \mathrm{p}=0.23$ ). The number of missing urines was greater in the PLAC group ( $M=9.68, \mathrm{SD}=7.14$, Med=9) than in the M200 $(\mathrm{M}=7.25, \mathrm{SD}=6.95, \mathrm{Med}=5)$ or the $\mathrm{M} 400(\mathrm{M}=7.50, \mathrm{SD}=6.71, \mathrm{Med}=6.5)$ groups, but a negative binomial regression model found that the difference was not significant (Chisquare $(2)=3.84, \mathrm{p}=0.15)$.

\section{GEE Comparisons of Abstinence Rates}

Since we found poor concordance between patient self-reports and our objective UDS measure of abstinence, which is consistent with our prior experience (Dackis et al., 2005), we focused exclusively on the UDS results. Our primary analysis of the 24 UDS indicators was based on missing samples being imputed as cocaine positive. This assumption is commonly made in cocaine treatment research because missing samples are not ignorable, 
given the tendency for active users to miss clinic appointments. Our initial model included binary factors contrasting M200 and M400 with PLAC as well as linear, quadratic, and cubic time trends. We found no significant effects for either modafinil group relative to placebo (M200 vs PLAC: Chi-square $=0.12, \mathrm{p}=0.73$; M400 vs PLAC: Chi-square $=0.75$, $\mathrm{p}=0.39$ ). We extended the model to include group by time interactions, as the graphs suggested that the relative ordering of abstinence rates between the three groups varied across time. When these group by time interactions were included in the model, there was some evidence of significant differences among the time courses of the three groups, with significant or nearly significant linear (M200 vs PLAC: Chi-square(1) $=7.95, p=0.005 ;$ M400 vs PLAC: Chi-square $(1)=4.58, p=0.03)$, quadratic $(\mathrm{M} 200$ vs PLAC: Chi-square(1)=5.12, $\mathrm{p}=0.02$; M400 vs PLAC: Chi-square $=3.59, \mathrm{p}=0.06$ ), and cubic (M200 vs PLAC: Chisquare $(1)=3.61, \mathrm{p}=0.06 ;$ M 400 vs PLAC: Chi-square $(1)=3.47, \mathrm{p}=0.06)$ time trends.

The differences in time course resulted from initial lower cocaine abstinence in the M200 versus PLAC group and very little subsequent separation among the three groups. In particular, within-time point contrasts showed that the difference between M200 and PLAC was significant at the first and second visits, with the odds for abstinence in M200 being 0.40 times that of the PLAC group (chi-square $(1)=8.80, \mathrm{p}=0.003$ ) at the first visit, with a corresponding odds ratio of 0.55 at the second visit (chi-square $(1)=5.11, p=0.02$ ). Similar contrasts at other time points showed that each of the modafinil groups had slightly higher odds of abstinence than the PLAC group, but the differences were generally not significant with (p-values ranging from 0.07 to 0.80). Only the comparison of M400 with PLAC at visit 24 was significant $(\mathrm{OR}=2.13,95 \%$ confidence interval $(1.04,4.35), \mathrm{p}=0.04)$. The corresponding GEE and mixed effects analyses with missing visits ignored showed similar patterns, but the differences were smaller and there were fewer significant comparisons. Very similar results were found when both modafinil groups were combined and compared to placebo, and when an 8-week time scale was used rather than a 24-visit time scale.

\section{The Role of Gender}

There was a significant gender by M400 interaction (Chi-square $=4.28, \mathrm{p}=0.04)$ with respect to UDS outcomes. To investigate this suggestion that modafinil efficacy might vary across gender, we fit models separately to the males and females in the sample. The study randomized a total of 155 males $(\mathrm{PLAC}=56, \mathrm{M} 200=47, \mathrm{M} 400=52$ ) and 55 females (PLAC=19, M200=18 M400=18). We observed a similar pattern to that of the full sample analyses, with the placebo group doing better than the two modafinil groups in the very early visits, followed by the two modafinil groups doing better than placebo for the rest of the treatment phase. There was some evidence that high dose modafinil was associated with higher rates of abstinence among males. For a main effects model, the estimated odds ratio for abstinence in the M400 group versus PLAC was 1.77, with 95\% confidence interval $(0.99,3.19)$ and a p-value of 0.06 . The corresponding odds ratio for the M200 group was 1.32 , with $95 \%$ confidence interval $(0.76,2.29)$ and a p-value of 0.32 , so there is little evidence in favor of the M200 group. Figure 3 shows the plot of abstinence rates for the male patients. An entirely different pattern was observed for the females (see Figure 4). Group by time effects did not approach significance and a main effects model suggested that the PLAC group had the highest rates of abstinence and the M400 group had the lowest rates of abstinence. However, the overall effect was not significant (Chi-square $(2)=2.28, p=0.32$ ). The corresponding GEE and mixed effects models when missing UDS responses were ignored showed no significant effects.

Since we found these gender specific results for the primary UDS outcome, we conducted separate analyses for males and females on the secondary outcomes during treatment and at the follow-up time points. There were no significant effects for males or females during treatment on the CSSA, CGI-O, CGI-S or BSCS. With regard to follow-up time points, there 
were stronger effects on the UDS outcomes in the males than in the overall sample. At visit $21,48 \%$ (23/48) of the M400 patients but only $16 \%$ (5/32) of the PLAC patients had cocaine-free urines. In addition, the M400 group had higher rates of abstinence than the PLAC group at each follow up point; week $10(\mathrm{OR}=2.23,95 \%$ confidence interval $(0.91$, 5.48), $\mathrm{p}=0.08)$; week 13 (OR=2.91, 95\% confidence interval $(1.13,7.51), \mathrm{p}=0.03)$; week 21 (OR=3.75, 95\% confidence interval $(1.47,9.54), \mathrm{p}=0.01)$. The differences between M200 and PLAC did not approach significance at any of the follow up points.

\section{Secondary Outcomes}

The rates of achieving three-weeks of continuous abstinence, with missed visits regarded as use, were not significantly different across the PLAC (30.7\%), M200 (35.4\%) and M400 $(32.9 \%)$ groups $($ Chi-square $=0.35, \mathrm{df}=2, \mathrm{p}=0.84)$.

Patient-Reported Cocaine Severity (CGI-S)—Clinical Global Improvement ScaleSelf (CGI-S) ratings showed no differences between the M200, M400 and PLAC groups in reported severity of cocaine dependence or associated functional impairment (GEE model $\mathrm{M} 200 \mathrm{Z}$-score $=1.42, \mathrm{p}=0.16, \mathrm{M} 400 \mathrm{Z}$-score $=0.77, \mathrm{p}=0.44$ ). There were no differences when male patients were analyzed separately.

Physician-Rated Assessments (CGI-O)—The study physician rated the Clinical Global Improvement Scale-Observer (CGI-O) summary scales each week. For the Global Severity of Cocaine Dependence Scale there were no treatment group differences found (M200 GEE model Z-score $=1.41, \mathrm{p}=0.16, \mathrm{M} 400 \mathrm{Z}$-score $=-0.25, \mathrm{p}=0.80$ ). For the Global Improvement of Cocaine Dependence of the CGI-O, there were significant group by linear time effects (GEE model M200 Z-score $=-2.58, \mathrm{p}=0.01$, M400 Z-score $=-2.10, \mathrm{p}=0.04$ ) but with the PLAC group showing greater clinical global improvement than the M200 group. When males were analyzed separately, the PLAC group still had higher scores on clinical improvement (beta $=0.3812, \mathrm{p}=0.01,95 \%$ confidence interval $(0.1043,0.6581)$ ) but the M400 group had a trend for lower severity than placebo at week 21 (beta=0.3030, $\mathrm{p}=0.07$, $95 \%$ confidence interval $(-0.0285,0.6346))$.

Cocaine Craving and Withdrawal (CSSA, BCSC)-There were no treatment group differences in the total Cocaine Selective Severity Assessment (CSSA) scores (M200 chisquare $(1)=0.18, p=0.68 ; \mathrm{M} 400$ chi-square $(1)=0.01, \mathrm{p}=0.94)$. These statistics were based on GEE models of log transformed CSSA total scores over the 8 weeks of medication in the study. Similar analyses for the "Intensity of Craving" item (M200 chi-square $(1)=0.46$, $\mathrm{p}=0.50$; M400 chi-square $(1)=1.93, \mathrm{p}=0.16)$ and the "Frequency of Craving" item (M200 chisquare $(1)=0.01, \mathrm{p}=0.91 ; \mathrm{M} 400$ chi-square $(1)=0.96, \mathrm{p}=0.33)$ also showed no significant group effects.

There were no significant treatment group differences in the BSCS Intensity (M200 chisquare $(1)=0.39, \mathrm{p}=0.53 ; \mathrm{M} 400$ chi-square $(1)=1.32, \mathrm{p}=0.25)$, Frequency $(\mathrm{M} 200$ chisquare $(1)=0.03, \mathrm{p}=0.85 ; \mathrm{M} 400$ chi-square $(1)=0.66, \mathrm{p}=0.42$ ), Craving Duration (M200 chisquare $(1)=0.69, \mathrm{p}=0.41 ; \mathrm{M} 400$ chi-square $(1)=0.56, \mathrm{p}=0.45)$ or Craving Frequency scales (M200 chi-square $(1)=0.15, \mathrm{p}=0.70 ; \mathrm{M} 400$ chi-square $(1)=0.79, \mathrm{p}=0.37$ ) based on log transformed number of times.

We found the same pattern of results when these CSSA and BSCS analyses were repeated within the male patients.

Abstinence in Final Three Weeks of Treatment-The following table shows the rates of complete abstinence in the final three weeks of the study. Patients were regarded as 
abstinent if they attended each of their last nine scheduled visits and provided cocainenegative urines on each occasion. The overall test for the full table was not significant (Chisquare $(2)=3.85, \mathrm{p}=0.15$ ) but the M400 group showed a trend towards higher rates of complete abstinence $(\mathrm{OR}=3.10, \mathrm{p}=0.06)$.

End of Study Questionnaire-A questionnaire was added to our study at about midpoint to further delineate the effect of modafinil on craving and cocaine-induced euphoria. A total of 91 patients responded to this questionnaire and we analyzed the 88 who used cocaine during the trial. Patients were asked to rate (1) cocaine-induced euphoria, (2) cue-induced craving, (3) cocaine-induced craving and (4) general craving during their 8week modafinil trial, with each item rated as "absent," "less than usual," "usual," or "more than usual." We combined "absent" with "less than usual" responses, as well as "usual" with "greater than usual" responses for our analysis. With regard to (1) cocaine-induced euphoria, the difference between modafinil (M200 and M400) compared to PLAC approached statistical significance (chi-square $(1)=3.35, \mathrm{p}=0.07$ ). For each of the craving measures, the combined modafinil group had higher rates of "absent" or "less than usual" craving, but the differences were not significant for (2) cue-induced craving (chi-square $(1)=1.60, p=0.21$ ), general craving (chi-square $(1)=2.65, \mathrm{p}=0.10$ ) or cocaine-induced craving (chisquare $(1)=2.74, \mathrm{p}=0.10)$.

Follow-Up Time Points-Self-reported cocaine abstinence rates at follow-up (weeks 10, 13, and 21) did not differ across the three treatment groups. UDS abstinence was similar for weeks 10 and 13, but there were differences at week 21 in the percent of cocaine-free urines for the PLAC (16\%), M200 (15\%) and M400 (33\%) groups. An overall test of association was significant (Chi-square $(2)=8.15,, p=0.02$ ), and the odds ratio for abstinence in the M400 group relative to the PLAC group at week 21 was 2.57 ( $\mathrm{p}=0.02)$.

Within males, there were stronger effects. At visit 21, 48\% (23/48) of the M400 patients but only $16 \%$ (5/32) of the PLAC patients had cocaine-free urines. With a missing UDS imputed as positive, the M400 group had higher rates of abstinence than the PLAC group at each follow up point; week $10(\mathrm{OR}=2.23,95 \%$ confidence interval $(0.91,5.48), \mathrm{p}=0.08)$; week $13(\mathrm{OR}=2.91,95 \%$ confidence interval $(1.13,7.51), \mathrm{p}=0.03)$; week $21(\mathrm{OR}=3.75,95 \%$ confidence interval $(1.47,9.54), \mathrm{p}=0.01)$. The differences between M200 and PLAC did not approach significance at any of the follow up points.

Depression and Anxiety symptoms-The Beck depression inventory was obtained at weeks 0 through 8 and weeks 10,13, and 21, while the Hamilton anxiety and depression scales were obtained at weeks $0,10,13$, and 21. Scores on the total scores for all three scales decreases from baseline (week 0 ) through the treatment phase (to week 10), with little change between weeks 10 and 21 . There were no significant differences in time course across the groups, and the main effects of group were not significant: BDI in treatment phase $-\mathrm{F}(2,198)=0.07, \mathrm{p}=0.93$, BDI in follow-up phase $-\mathrm{F}(2,154)=0.04, \mathrm{p}=0.96$; HAM$\mathrm{A}$ in follow-up phase $-\mathrm{F}(2,151)=1.67, \mathrm{p}=0.19$; HAM-D in follow-up phase $-\mathrm{F}(2,137)=$ $0.71, \mathrm{p}=0.50$. We note that there were 161 subjects available for the BDI and 164 subjects available for the Hamilton scales for the follow-up analyses. The variation in degrees of freedom reflects the use of the Kenward-Rogers option for denominator degrees of freedom in the test statistics. There were no gender by group differences on any of these outcomes.

\section{Tolerability}

There were no clinically significant differences between the two groups with regard to laboratory, vital sign, electrocardiogram, body weight, or physical examination findings. There was only one serious adverse events thought to be related to study medications. This 
involved treatment emergent mania in a patient who was using large amounts of cocaine and required psychiatric hospitalization. He was diagnosed with bipolar affective disorder and discontinued from the study medications. Adverse events occurring in at least 5\% of modafinil patients, and with at least twice the incidence of occurrence in placebo patients, included upper respiratory symptoms (25\%), headaches (23\%), insomnia (11\%), weight loss $(9 \%)$ and nausea $(9 \%)$. None of the patients ascribed euphoria or cocaine-like effects related to the study medications.

\section{DISCUSSION}

This study did not find a significant main effect of modafinil on the rate or duration of cocaine use among cocaine dependent patients. Accordingly, we failed to confirm earlier encouraging reports that modafinil promotes abstinence in cocaine dependence (Anderson et al., 2009; Dackis et al., 2005). Although these results are disappointing, we did find that modafinil-treated patients had non-significantly higher odds of attaining abstinence across all of the study time points, and those treated with $400 \mathrm{mg} /$ day had significantly greater odds of attaining abstinence $(\mathrm{p}=0.04)$ at the end of their 8 -week medication trial (visit 24). There was also a significant difference $(\mathrm{p}=0.02)$ in the odds ratio for abstinence at the final followup visit, suggesting the possibility that modafinil facilitated delayed clinical improvement that was not captured by our 8-week study design.

We also found a significant gender effect with the male patients showing a much better response to $400 \mathrm{mg} /$ day of modafinil than placebo. A post hoc analysis of males $(\mathrm{n}=155)$ treated with $400 \mathrm{mg} /$ day of modafinil revealed an estimated odds ratio for abstinence of 1.77 $(\mathrm{p}=0.06)$, which just missed reaching statistical significance, although the lower dose of modafinil (200 mg/day) had a much less impressive odds ratio of 1.32 for cocaine abstinence $(\mathrm{p}=0.32)$. There were also higher rates of abstinence in males treated with modafinil $400 \mathrm{mg} / \mathrm{day}$ at each of the three follow-up evaluations, with increasing significance when comparing week $10(\mathrm{p}=0.08)$ to weeks $13(\mathrm{p}=0.03)$ and $21(\mathrm{p}=0.01)$. At week $21,48 \%$ of the patients treated with modafinil $400 \mathrm{mg} /$ day but only $15 \%$ of those on placebo had cocaine-free urines, again suggesting the possibility of a delayed benefit in patients treated with the higher dose of modafinil. However, demonstrating a delayed response would require additional investigation and we are concluding that this study is a negative trial of modafinil during the 8-week medication course. Despite its ability to blunt cocaine-induced euphoria in three controlled human laboratory studies (Dackis et al., 2003; Hart et al., 2008; Malcolm et al., 2006), modafinil did not show overall success in this outpatient clinical trial.

It is important to note that all of the patients in this study tested positive for cocaine at baseline. It is well established that patients who test positive for cocaine at study start have extremely poor clinical outcomes when compared those who are able to produce a cocainenegative urine sample (Ahmadi et al., 2009; Kampman et al., 2001; Patkar et al., 2002; Poling, Kosten, \& Sofuoglu, 2007). The reason for this finding is unclear, but it probably stems from greater addiction severity, less motivation for recovery, or both of these clinical features. Since the standard of care for severely addicted cocaine patients typically involves intensive outpatient or even inpatient treatment (Dackis \& O'Brien, 2001), and the current study provided only one CBT session per week, our negative results might be explained by the absence of an adequate psychosocial platform.

Despite our negative study, we believe it is premature to dismiss modafinil as a potential treatment for cocaine dependence. Two of three clinical trials are positive, and modafinil has been reported to blunt cocaine-induced euphoria in three controlled human laboratory studies (Dackis et al., 2003; Hart et al., 2008; Malcolm et al., 2006). Since cocaine 
dependence is primarily driven by euphoria and craving (Dackis \& O'Brien, 2001), attenuating its rewarding effect should provide treatment advantage that might not be discernable in an 8-week clinical trial. We also report significant beneficial effects in males treated with the higher dose of modafinil in the current study. Further research is warranted to elucidate a possible gender effect and determine whether modafinil might benefit cocaine dependent patients who are also receiving intensive drug rehabilitation.

\section{Acknowledgments}

Funding/Support: Funding for this trial was provided by the National Institute of Drug Abuse (NIDA) Grant RO1 DA015366-01. Cephalon provided modafinil and matched placebo tablets.

Investigators: Dackis, Kampman, Pettinati, O’Brien

Sponsor: Dr. Dackis was the sponsor and the principal investigator.

\section{References}

Ahmadi J, Kampman KM, Oslin DM, Pettinati HM, Dackis C, Sparkman T. Predictors of treatment outcome in outpatient cocaine and alcohol dependence treatment. Am J Addict. 2009; 18(1):81-86. [PubMed: 19219669]

Anderson AL, Reid MS, Li SH, Holmes T, Shemanski L, Slee A, Smith EV, Kahn R, Chiang N, Vocci F, Ciraulo D, Dackis C, Roache JD, Salloum IM, Somoza E, Urschel HC, Elkashef AM. Modafinil for the treatment of cocaine dependence. Drug Alcohol Depend. 2009; 104(1-2):133-139. [PubMed: 19560290]

Beck AT, Weissman A, Lester D, Trexler L. The measurement of pessimism: the hopelessness scale. J Consult Clin Psychol. 1974; 42(6):861-865. [PubMed: 4436473]

Bell K, Duffy P, Kalivas PW. Context-specific enhancement of glutamate transmission by cocaine. Neuropsychopharmacology. 2000; 23(3):335-344. [PubMed: 10942857]

Dackis C, Lynch K, Kampman K, Pettinati H, O’Brien C. Do self-reports reliably assess abstinence in cocaine dependent patients? Neuropsychopharmacology. 2005; 30(12):2299-2300.

Dackis C, O'Brien C. Glutamatergic agents for cocaine dependence. Ann N Y Acad Sci. 2003; 1003:328-345. [PubMed: 14684456]

Dackis CA. New treatments for cocaine abuse. Drug Discovery Today. 2005; 2(1):79-86.

Dackis, CA.; O'Brien, CP. The neurobiology of alcoholism. In: Soires, JC.; Gershon, S., editors. Handbook of Medical Psychiatry. New York: Marcel Dekker; 2003. p. 563-580.

Dackis CA, Kampman KM, Lynch KG, Pettinati HM, O'Brien CP. A double-blind, placebo-controlled trial of modafinil for cocaine dependence. Neuropsychopharmacology. 2005; 30(1):205-211. [PubMed: 15525998]

Dackis CA, Lynch KG, Yu E, Samaha FF, Kampman KM, Cornish JW, Rowan A, Poole S, White L, O'Brien CP. Modafinil and cocaine: a double-blind, placebo-controlled drug interaction study. Drug Alcohol Depend. 2003; 70(1):29-37. [PubMed: 12681523]

Dackis CA, O'Brien CP. Cocaine dependence: a disease of the brain's reward centers. J Subst Abuse Treat. 2001; 21(3):111-117. [PubMed: 11728784]

Deroche-Gamonet V, Darnaudery M, Bruins-Slot L, Piat F, Le Moal M, Piazza PV. Study of the addictive potential of modafinil in naive and cocaine-experienced rats. Psychopharmacology (Berl). 2002; (4):161. 387-395.

Derogatis LR. SCL 90, Administration, scoring and procedures. 1977 Unpublished manuscript.

Diggle, P.; Heagerty, P.; Liang, K.; Zeger, S. Analysis of Longitudinal Data. 2 ed.. Oxford: Oxford University Press; 2002.

First, MB.; Spitzer, RL.; Gibbon, M.; Williams, JBW. Structured Clinical Interview for DSM-IV Axis I Disorders - Subject Edition (SCID-I/P, Version 2.0). New York, New York: Biometrics Research Department New York State Psychiatric Institute; 1996. 
Gold LH, Balster RL. Evaluation of the cocaine-like discriminative stimulus effects and reinforcing effects of modafinil. Psychopharmacology (Berl). 1996; 126(4):286-292. [PubMed: 8878344]

Guy, W. Assessment Manual for Psychopharmacology: Publication ADM 76-338. Washington, DC: 1976. Unpublished manuscript

Hamilton M. Development of a rating scale for primary depressive illness. British Journal of Social and clinical Psychology. 1967; 6:278-296. [PubMed: 6080235]

Hamilton M. The assessment of anxiety states by rating. British Journal of Medical Psychology. 1969; 32:50-55. [PubMed: 13638508]

Hart CL, Haney M, Vosburg SK, Rubin E, Foltin RW. Smoked cocaine self-administration is decreased by modafinil. Neuropsychopharmacology. 2008; 33(4):761-768. [PubMed: 17568397]

Hotsenpiller G, Giorgetti M, Wolf ME. Alterations in behaviour and glutamate transmission following presentation of stimuli previously associated with cocaine exposure. Eur J Neurosci. 2001; 14(11): 1843-1855. [PubMed: 11860480]

Jasinski DR. An evaluation of the abuse potential of modafinil using methylphenidate as a reference. J Psychopharmacol. 2000; 14(1):53-60. [PubMed: 10757254]

Jasinski DR, Kovacevic-Ristanovic R. Evaluation of the abuse liability of modafinil and other drugs for excessive daytime sleepiness associated with narcolepsy [In Process Citation]. Clin Neuropharmacol. 2000; 23(3):149-156. [PubMed: 10895398]

Kadden, R.; Carroll, K.; Donovan, D.; Cooney, N.; Monti, P.; Abrams, D.; Litt, M.; Hestler, R. Cognitive-Behavioral Coping Skills Therapy Manual. Washington, D.C: U.S. Government Printing Office; 1992.

Kalivas PW, Duffy P. Repeated cocaine administration alters extracellular glutamate in the ventral tegmental area. J Neurochem. 1998; 70(4):1497-1502. [PubMed: 9523566]

Kampman KM, Volpicelli JR, McGinnis DE, Alterman AI, Weinrieb RM, D'Angelo L, Epperson LE. Reliability and validity of the Cocaine Selective Severity Assessment. Addictive Behaviors. 1998; 23:449-461. [PubMed: 9698974]

Kampman KM, Alterman AI, Volpicelli JR, Maany I, Muller ES, Luce DD, Mulholland EM, Jawad AF, Parikh GA, Mulvaney FD, Weinrieb RM, O'Brien CP. Cocaine withdrawal symptoms and initial urine toxicology results predict treatment attrition in outpatient cocaine dependence treatment. Psychol Addict Behav. 2001; 15(1):52-59. [PubMed: 11255939]

Keys AS, Mark GP, Emre N, Meshul CK. Reduced glutamate immunolabeling in the nucleus accumbens following extended withdrawal from self-administered cocaine. Synapse. 1998; 30(4): 393-401. [PubMed: 9826231]

Malcolm R, Swayngim K, Donovan JL, DeVane CL, Elkashef A, Chiang, N.. Khan R, Mojsiak J, Myrick DL, Hedden S, Cochran K, Woolson RF. Modafinil and cocaine interactions. Am J Drug Alcohol Abuse. 2006; 32(4):577-587. [PubMed: 17127546]

McLellan AT, Kushner H, Metzger D, Peters R, Smith I, Grissom G, Pettinati H, Argeriou M. The Fifth Edition of the Addiction Severity Index. J Subst Abuse Treat. 1992; 9(3):199-213. [PubMed: 1334156]

Mignot E, Nishino S, Guilleminault C, Dement WC. Modafinil binds to the dopamine uptake carrier site with low affinity. Sleep. 1994; 17(5):436-437. [PubMed: 7991954]

Myrick H, Malcolm R, Taylor B, LaRowe S. Modafinil: preclinical, clinical, and post-marketing surveillance--a review of abuse liability issues. Ann Clin Psychiatry. 2004; 16(2):101-109. [PubMed: 15328903]

O'Brien CP, Dackis CA, Kampman K. Does modafinil produce euphoria? Am J Psychiatry. 2006; 163(6):1109. [PubMed: 16741217]

Patkar AA, Thornton CC, Berrettini WH, Gottheil E, Weinstein SP, Hill KP. Predicting treatmentoutcome in cocaine dependence from admission urine drug screen and peripheral serotonergic measures. J Subst Abuse Treat. 2002; 23(1):33-40. [PubMed: 12127466]

Poling J, Kosten TR, Sofuoglu M. Treatment outcome predictors for cocaine dependence. Am J Drug Alcohol Abuse. 2007; 33(2):191-206. [PubMed: 17497542]

Preston KL, Silverman K, Schuster CR, Cone EJ. Assessment of cocaine use with quantitative urinalysis and estimation of new uses. Addiction. 1997; 92(6):717-727. [PubMed: 9246799] 
Rossetti ZL, Carboni S. Ethanol withdrawal is associated with increased extracellular glutamate in the rat striatum. Eur J Pharmacol. 1995; 283(1-3):177-183. [PubMed: 7498307]

Rush CR, Kelly TH, Hays LR, Wooten AF. Discriminative-stimulus effects of modafinil in cocainetrained humans. Drug Alcohol Depend. 2002; 67(3):311-322. [PubMed: 12127202]

Sheenan DV, Lecrubier Y, Sheehan K, Janavs J, Weiller A, Schinka J, Knapp E, Dunbar GC. The validity of the mini international interview (MINI) according to the SCID-P and its reliability. European Psychiatry. 1997; 12:232-241.

Shoptaw S, Kintaudi PC, Charuvastra C, Ling W. A screening trial of amantadine as a medication for cocaine dependence. Drug Alcohol Depend. 2002; 66(3):217-224. [PubMed: 12062456]

Sobell, L.; Sobell, M. Timeline follow-back: A technique for assessing self-reported alcohol. In: Allen, LA., editor. Measuring Alcohol Consumption. Totowa, NJ: The Humana Press; 1992.

Somoza, E.; Dyrenforth, S.; Goldsmith, J.; Mezinskis, J.; Cohen, M. In search of a Universal Drug Craving Scale; Paper presented at the Annual Meeting of the American Psychiatric Association; Miami, Florida. 1995.

Thomas MJ, Beurrier C, Bonci A, Malenka RC. Long-term depression in the nucleus accumbens: a neural correlate of behavioral sensitization to cocaine. Nat Neurosci. 2001; 4(12):1217-1223. [PubMed: 11694884]

Trujillo KA, Akil H. Excitatory amino acids and drugs of abuse: a role for N-methyl-D-aspartate receptors in drug tolerance, sensitization and physical dependence. Drug Alcohol Depend. 1995; 38(2):139-154. [PubMed: 7671766]

Volkow ND, Fowler JS, Logan J, Alexoff D, Zhu W, Telang F, Wang GJ, Jayne M, Hooker JM, Wong C, Hubbard B, Carter P, Warner D, King P, Shea C, Xu Y, Muench L, Apelskog-Torres K. Effects of modafinil on dopamine and dopamine transporters in the male human brain: clinical implications. Jama. 2009; 301(11):1148-1154. [PubMed: 19293415]

Vosburg SK, Hart CL, Haney M, Rubin E, Foltin RW. Modafinil does not serve as a reinforcer in cocaine abusers. Drug Alcohol Depend. 2009

Warot D, Corruble E, Payan C. Subjective effects of modafinil, a new central adrenergic stimulant in healthy volunteers: a comparison with amphetamine, caffeine, and placebo. Eur Psychiatry. 1993; 8:201-208.

Zolkowska D, Jain R, Rothman RB, Partilla JS, Roth BL, Setola V, Prisinzano TE, Baumann MH. Evidence for the involvement of dopamine transporters in behavioral stimulant effects of modafinil. J Pharmacol Exp Ther. 2009; 329(2):738-746. [PubMed: 19197004] 


\section{$334 \mathrm{~B}$ as eline $\mathrm{S}$ creening}

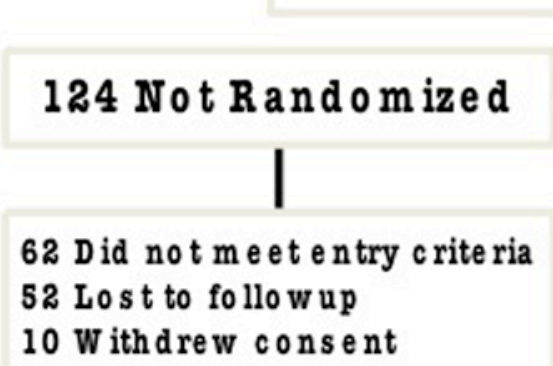

10 withdrew consent

\section{$210 \mathrm{R}$ and $0 \mathrm{mized}$}

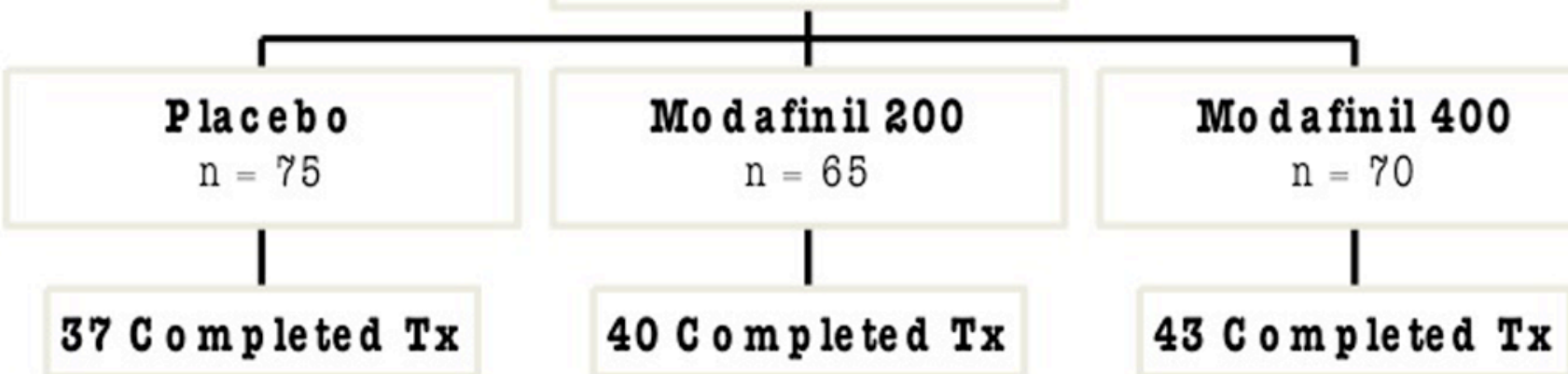

Figure 1.

Patient Flow 


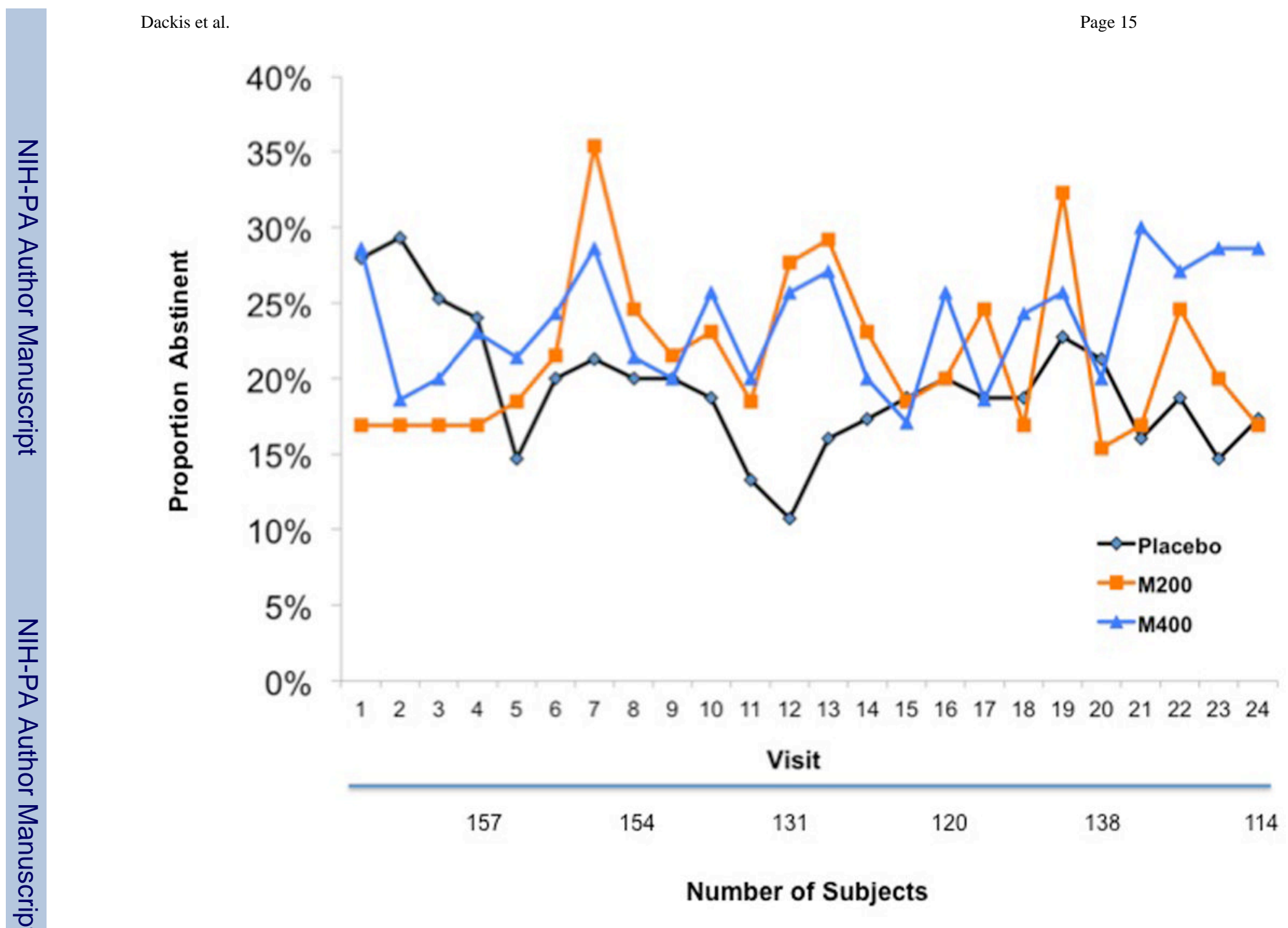

Figure 2.

Cocaine Abstinence Rates in the Overall Sample 


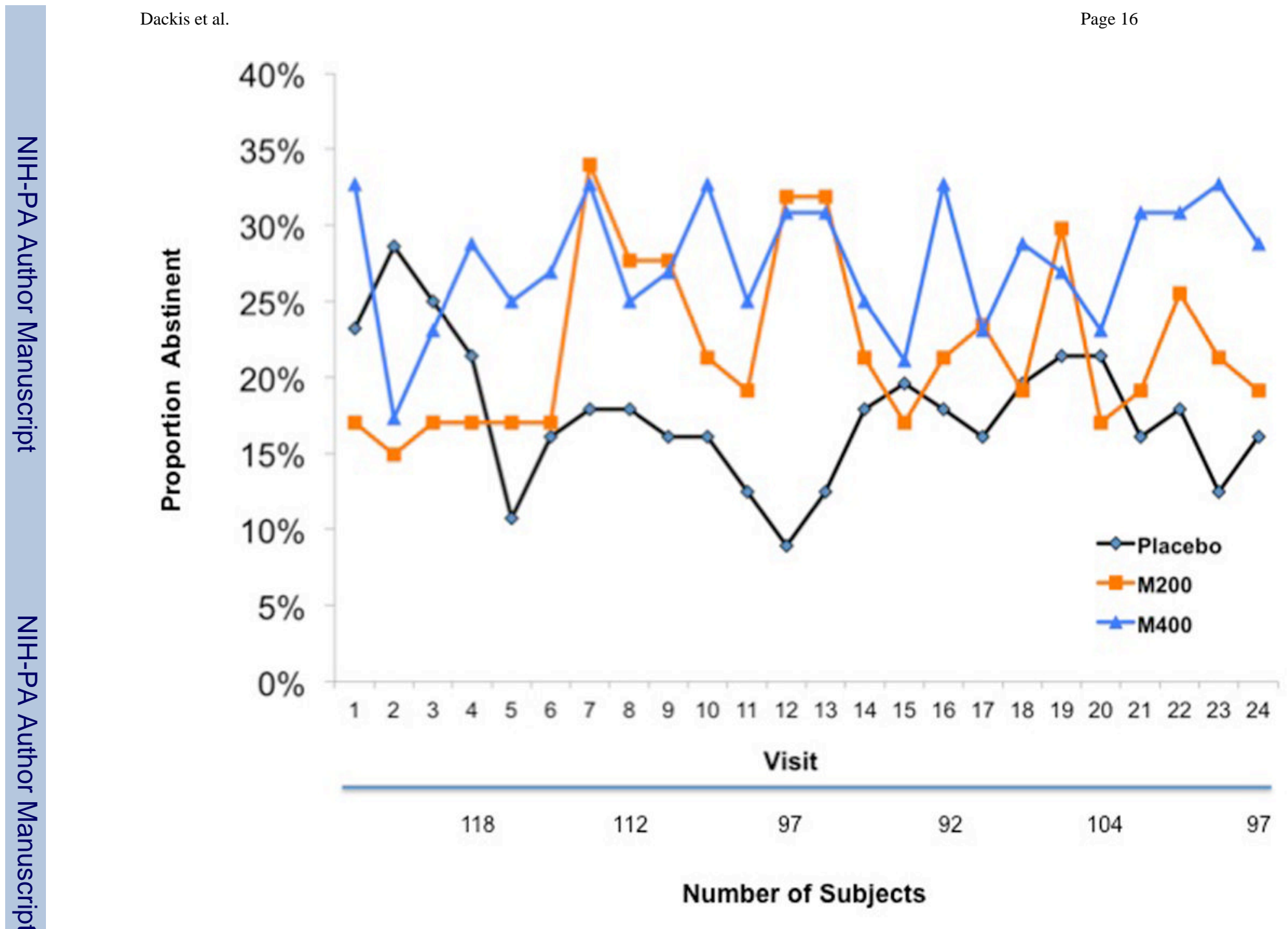

Figure 3.

Cocaine Abstinence Rates in the Male Patients

J Subst Abuse Treat. Author manuscript; available in PMC 2013 October 01. 


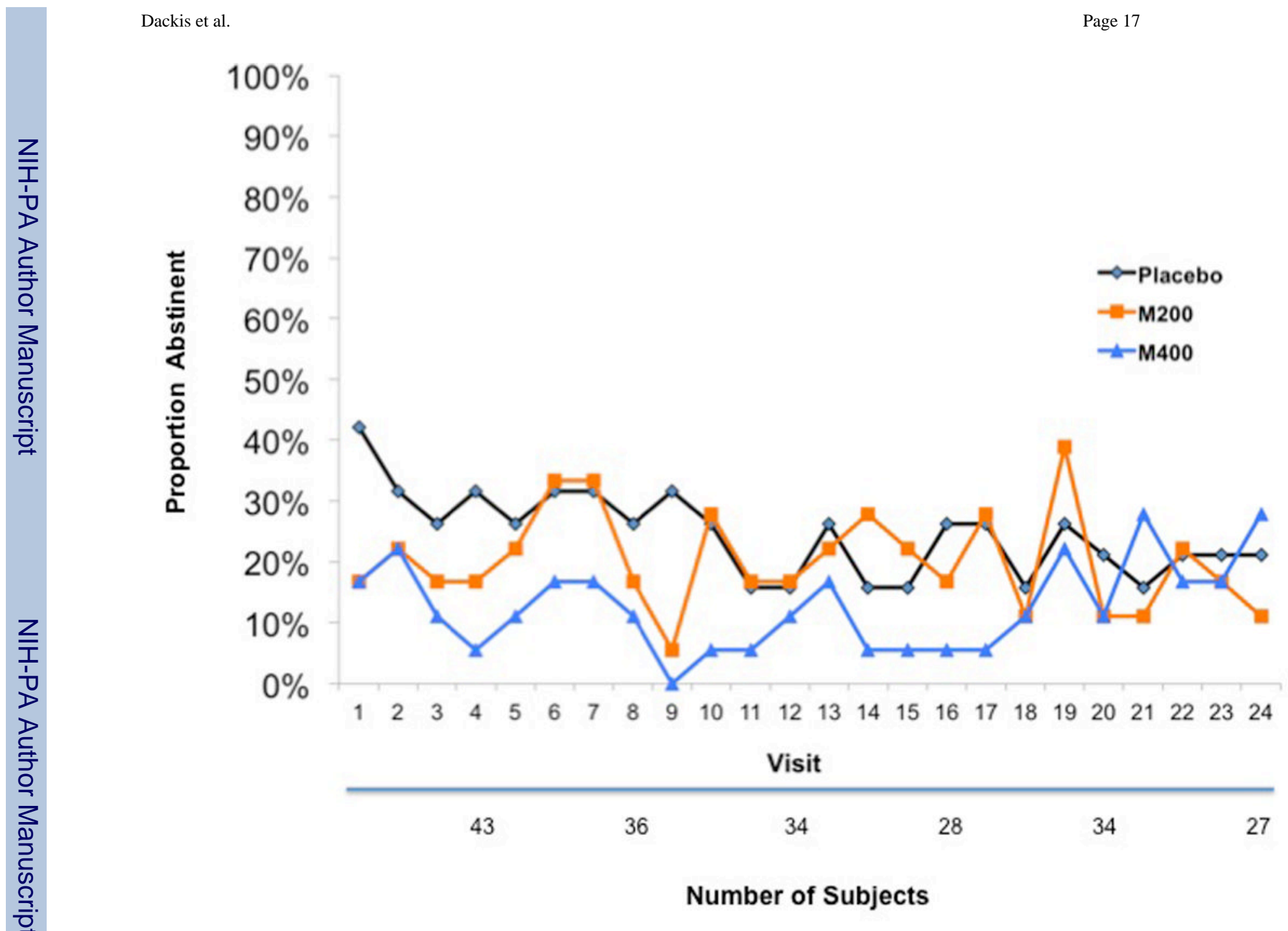

Figure 4.

Cocaine Abstinence Rates in the Female Patients

J Subst Abuse Treat. Author manuscript; available in PMC 2013 October 01. 
Table 2

Baseline Characteristics as Percentages or Means (Standard Deviations) with p-Values

\begin{tabular}{lllll}
\hline & $\begin{array}{l}\text { Modafinil 200 } \\
(\mathbf{n = 6 5})\end{array}$ & $\begin{array}{l}\text { Modafinil 400 } \\
(\mathbf{n = 7 0})\end{array}$ & $\begin{array}{l}\text { Placebo } \\
(\mathbf{n = 7 5})\end{array}$ & p-value \\
\hline Demographic & & & & \\
Age & $41.72(6.9)$ & $43.64(7.7)$ & $42.46(7.5)$ & 0.313 \\
\% Males & $72.31 \%$ & $74.29 \%$ & $74.67 \%$ & 0.945 \\
\% Married & $13.85 \%$ & $24.29 \%$ & $18.67 \%$ & 0.302 \\
Race (\% African American) & $80.00 \%$ & $81.43 \%$ & $74.67 \%$ & 0.578 \\
Total years of education & $12.94(2.0)$ & $13.06(2.2)$ & $13.03(2.4)$ & 0.948 \\
Days in last 30 employed & $10.31(10.1)$ & $11.45(10.8)$ & $12.42(10.4)$ & 0.493 \\
Clinical & & & & \\
\% crack (smoking) use & $75.38 \%$ & $82.61 \%$ & $77.03 \%$ & 0.562 \\
\% BE-positive baseline urines & $100.0 \%$ & $100.0 \%$ & $92.00 \%$ & 0.004 \\
CSSA scores at baseline & $23.03(17.5)$ & $25.68(16.8)$ & $27.32(20.1)$ & 0.395 \\
Days of cocaine use/week & $2.81(2.0)$ & $2.67(2.1)$ & $2.57(2.0)$ & 0.801 \\
Weekly cocaine cost & $137.8(176)$ & $202.7(396)$ & $232.1(452)$ & 0.312 \\
Years of cocaine use & $13.75(7.7)$ & $14.32(7.1)$ & $13.24(7.2)$ & 0.680 \\
Hamilton Anxiety Scale & $8.89(5.6)$ & $9.13(5.4)$ & $9.32(5.7)$ & 0.906 \\
Hamilton Depression Scale & $14.52(9.2)$ & $15.37(9.5)$ & $15.90(9.8)$ & 0.692 \\
Beck Depression Inventory & $14.84(9.3)$ & $17.33(9.6)$ & $16.71(11.3)$ & 0.351 \\
SCL-90 total score & $52.83(54.0)$ & $67.53(55.9)$ & $63.57(59.9)$ & 0.318 \\
Antisocial Personality Disorder & & & & \\
\hline
\end{tabular}


Table 2

Abstinence in the final three weeks of treatment.

\begin{tabular}{|l|c|c|c|}
\hline Status & Placebo & M200 & M400 \\
\hline Abstinent & 4 & 3 & 8 \\
\hline$\%$ Abstinent & $4 \%$ & $5 \%$ & $11 \%$ \\
\hline Not abstinent & 72 & 62 & 62 \\
\hline Total & 75 & 65 & 70 \\
\hline
\end{tabular}

